\title{
Scientific Exhibition at British Association Meeting.
}

THE ninety-first annual meeting of the British Association, which has just drawn to a close at Liverpool, was characterised by a new and important departure in the form of an exhibition of scientific apparatus, instruments, and diagrams. The exhibition was on the lines of that organised each year in London by the Physical and Optical Societies, which is so effective in bringing together the users and makers of physical apparatus, but its scope was naturally wider, and many branches of pure and applied science were represented.

In opening the exhibition on Monday, September Io, Sir Charles Sherrington commented upon the comprehensive and representative character of the exhibits, remarking that it was very appropriate that such a collection should be brought together, and that this--the first of its kind--constituted a definite development in the history of the British Association. He further referred to the remarkable advances in the making of scientific instruments during the last three hundred years, to the ever-growing importance of instrumentation, and to the unavoidable complexity of the apparatus needed for some of the simplest and therefore the most fundamental of scientific inquiries.

Admission to the exhibition was not confined to members of the British Association, to whom it was free, but the doors were opened to any member of the public on payment of the moderate sum of one shilling for one day only, while three times that amount guaranteed admission at any time during the fortnight of the exhibition. The results for the first week show that this arrangement was happily inspired, and that the exhibition was as popular with the outside public as with members of the Association. The number of daily tickets sold was quite naturally largely in excess of the number of season tickets, but the demand for the latter was quite sufficient to justify their issue.

The exhibition committee was fortunate indeed in having at its disposal the excellent accommodation afforded by the Central Technical Schools, Byrom Street, and the exhibits occupied the rooms on three floors of this magnificent building. The fine lecture hall enabled daily lectures, in some cases illustrated by cinematograph films or experiments, to be given by men of science, a feature which contributed in no small degree to the success of the exhibition. The popularity of these lectures is sufficiently illustrated by the fact that arrangements were made for two at least to be delivered a second time-" The Optophone," by Prof. Barr, and " Researches in Special Steels," by Mr. S. A. Main (Research Department of Sir Robert Hadfield's, Ltd.). Other lectures included " Ripples," by Prof. L. R. Wilberforce; "Research and Industry," by Sir Frank Heath; "Experiments on Coal Dust Explosions in Mines," by Prof. H. B. Dixon; "The Compass in Navigation," by Capt. Creagh-Osborne, R.N.; " Flame," by Prof. A. Smithells; " Kodachrome Cinematograph," by Dr. Mees (Kodak Co., London); "Developments in Wireless Telegraphy," by Commander Slee (Marconi Co., London).

Much attention was attracted by demonstrations, daily throughout the meeting, of the photophone exhibited by Prof. A. O. Rankine, and the optophone (Barr and Stroud, Ltd.). In the former, the transmitter or light modulator was installed in a room in St. George's Hall, and the beam of light, fluctuating in sympathy with the vibrations constituting the sounds to be transmitted, was thrown across the intervening space of some two hundred yards to the room in the Central Technical Schools where the receiving apparatus was located. The fluctuating light here controlled the electric current in a selenium cell, and the variable current actuated a telephone receiver. In this way demonstrations were given of the transmission of speech and music, and these made, in particular, a wide appeal to the lay mind, a result largely assisted by publicity given by the Press.

No less popular were the demonstrations of the optophone, the purpose of which is to enable the blind to read ordinary printed matter. In this, a selenium bridge is exposed to successions of sets of light pulsations, which vary with the forms of the letters passed over. Characteristic musical sounds are produced in a telephone receiver by each letter, constituting an alphabet readily learned.

The exhibition committee received the support of the National Physical Laboratory and of the Meteorological Office, Air Ministry. The exhibit of the former consisted very appropriately of specimen lenses for use in ships' lights, and master standards of colour for testing the colour screens of ships' lights. These were in accordance with the recommendations made in the Report of the Departmental Committee on Ships' Navigation Lights (1922), and formed an instructive display.

The exhibit provided by the Meteorological Department of the Air Ministry followed closely the lines of demonstrations given by that department at the two previous meetings of the Association, in Hull and Edinburgh. A wireless receiving set was employed to intercept the broadcast messages forming the daily international exchange of weather information, and, from these, weather charts were prepared, and forecasts made for the Liverpool area and the Irish Sea. Visitors were, in fact, able to see in miniature the complete working of a weather forecast service. These demonstrations were supplemented by a display of up-to-date meteorological instruments, and by diagrams and photographs of geophysical interest. Much interest was shown in the record of the recent earthquake in Japan, taken at the Bidston Observatory, and in a set of charts showing the progress of the depression which caused the destructive gales of August 29-30 of this year. One of these charts showed the depression completely defined over the Atlantic by one of the best sets of simultaneous observations from ships ever received in the Meteorological Office, and the accuracy of the forecasts issued on that occasion emphasises the practical importance of such reports.

One impression gained by a visit to the exhibition was that the field covered by the exhibits was not only a wide one, but also that very great care had been exercised in the choice of the material shown, having regard to the position of Liverpool as a great seaport and its location in an industrial area. It is not possible to deal in detail with the many interesting and instructive things which were to be seen, comprising, as they did, many striking exhibits in wireless transmission, in the manufacture of steel, in optical and electrical instruments, in instruments employed in navigation, including the gyro-compass, in the chemical and dye industries, in the manufacture of glass, in chemical apparatus, in recorders for use in the control of fuel combustion, in photography and photomicrography, in meteorological instruments, and in other branches of science and industry. Among the instruments which attracted special attention was K. C. Cox's selenium magnifier (H. W. Sullivan, Ltd.), which was shown working in connexion with a syphon recorder for long-distance submarine cable signalling, and is capable of giving magnification up to ten 
thousand times the received signal, and higher in special cases. New wireless apparatus, shown by the Marconi International Marine Communication Co., Ltd., embraced direction finders for use in ships, a special installation for ships' lifeboats including direction-finding equipment, and a duplex telephone setdesigned to enable ships within 50 miles of land to communicate by telephony with offices on land, utilising on land the ordinary telephone installation. The last is at present under trial at Southampton in co-operation with the General Post Office. Other very recent apparatus included a small $\mathrm{X}$-ray spectrograph (Adam Hilger, Ltd.), made to the design of Dr. A. Müller, embodying details valuable for the analysis by crystal structure of crystals and powders, and a barograph of special construction for survey work (by Negretti and Zambra). The latter has a range of 4 inches on the chart to represent $I$ inch variation of barometric pressure, and the instrument can be set to a standard barometer, anywhere from 25 in. to $3^{\mathrm{r}}$ in. of mercury, the temperature compensation being effective over this range. Mr. S. G. Brown's frenophone was another exhibit on which attention was focussed. This is a new "loud speaker" in which magnification of sound is obtained by an ingenious mechanical device dependent on the great friction existing between cork and glass.

But, in the space of a short article, justice cannot be done to all the interesting and instructive exhibits contained in the convenient and well-illustrated handbook issued by the exhibition committee. The local officers of the Association, the exhibition committee, and, in particular, the chairman of the committee, Capt. F. W. Bain, are to be congratulated on the success of this new departure, and it is to be hoped that they may be rewarded by seeing the present exhibition as the first of a long series in future years.
M. A. Gibletr.

\section{Terrestrial Magnetism in France. ${ }^{1}$}

$\mathrm{A}^{\mathrm{D}}$

DECREE of July 28 , I92 I, created an Institute of Geophysics attached to the Faculty of Science of the University of Paris, and the new institute has assigned to it the work in terrestrial magnetism previously entrusted to the Meteorological Service. There was established at the same time a Central Bureau of Terrestrial Magnetism for France and her colonies. The director of both bodies is the editor of the volume under notice, Prof. Ch. Maurain. $\mathrm{He}$ contributes an historical account of magnetic observations in France, and a study of disturbances due to electric traction. Recent magnetic history in France, as elsewhere, is mainly a tale of the devastating effects of electric traction. Parc St. Maur, which commenced its career as a magnetic observatory in I883, had to be replaced in Igor by Val Joyeux, and fears are now entertained for the future of Val Joyeux. There are already two electric lines in the district, one coming within 4400 metres, the other within 3000 metres of the observatory.

A discussion by M. Baldet of observations made at Berizaréa in Algeria represents magnetic work done in the colonies. The greater part of the volume, pp. 38-249, is, however, devoted to a discussion by M. Ch. Dufour of the magnetic observations at Val Joyeux from I9I 5 to I92I. This practically represents seven years' work rolled into one. In the earlier part of the memoir the results of the same species for the seven years appear in immediate succession. Thus we have $9 \frac{1}{2}$ consecutive pages of Fourier coefficients for the diurnal variation of $D$ (declination) and $\mathrm{H}$ (horizontal force) calculated for every month from January I9I 5 to December I92I, while pp. 60-94 are devoted to a description of the magnetic disturbances recorded during the 84 successive months. The principal magnetic storms are dealt with in 23 plates at the end of the volume, $Z$ (vertical force) curves being reproduced as well as $\mathrm{D}$ and $\mathrm{H}$. The time scale is only I $\mathrm{cm}$. to the hour, and details of rapid oscillations are difficult to follow, especially for the largest storms, among which the storm of May I4-I5, I92I, is pre-eminent. A rather unusual feature is that movement up the sheet represents decrease in all three elements. On p. 95 is a résumé of mean absolute values of seven elements at Val Joyeux from I9OI to I92I. The plan of the work then alters, the years being treated separately. The material given for each year has some special features.

1 Annales de l'Institut de Physique du Globe de l'Université de Paris et du Bureau Central de Magnétisme Terrestre. Publiées par les soins de Prof. Ch. Maurain. Tome Premier. (Paris: Les Presses universitaires de France, 1923.)
There are, first, for each month mean daily values for $D, H$, and $Z$, and hourly values confined to $6 \mathrm{~h}$, $\mathrm{I} 2 \mathrm{~h}, \mathrm{I} 8 \mathrm{~h}$, and $24 \mathrm{~h}$. The absolute daily maximum and minimum of $D$ and their times of occurrence are included, and a word or two describes the character of the day. Then follow diurnal inequalities for the I 2 months, apparently from all days, for 7 elements, and a table containing mean values for the 24 hours of the representative day of the year, derived respectively from all days and from quiet days. Following this is a most elaborate presentation of results from the five international quiet days of each month. Absolute values are given for each hour of each day for six elements.

The last part of the volume, pp. 250-298, contains a most valuable discussion of the magnetic results at Parc St. Maur and Val Joyeux from 1883 onwards by the veteran magnetician, M. A. Angot, late director of the Meteorological Bureau. This is a perfect mine of information for the magnetician. We have first diurnal inequalities for $\mathrm{D}, \mathrm{H}, \mathrm{Z}$, and I (inclination) for the twelve months, derived independently from I 8 years' records at Parc St. Maur, and from 17 years' records at Val Joyeux, stations both in the neighbourhood of Paris. Then we have diurnal inequalities for seven elements based on the whole 35 years, and ascribed to Paris. Following this there are Fourier coefficients for the 24-, 12-, 8-, and 6-hour waves corresponding to these inequalities. An elaborate investigation is made into the possibility of representing the annual change in the amplitude and phase of the several Fourier waves in terms of the longitude of the sun in its apparent annual path.

Another question minutely considered is the annual variation, meaning thereby the variation left in the mean monthly values of the elements after the elimination of the secular changes, assumed to progress at a uniform rate throughout the year. Use is made of mean monthly values of seven elements from I 883 to 1920 , recorded in tables on pp. $278-284$. The range obtained for the annual inequality in $D, 0 \cdot 23^{\prime}$, seems the smallest found anywhere as yet, but a suspicious feature in previous results has been the tendency for the apparent range to diminish as the number of years available has increased. For most of the other elements there are quite substantial ranges, e.g. $0.80^{\prime}$ in $\mathrm{I}$ (maximum in November, minimum in June), and $I 7 \cdot 3 \gamma$ in $H$ (maximum in June, minimum in November). The ranges for these two elements are somewhat larger than those found for $\mathrm{Kew}^{2}$ from a shorter period of years, but the ${ }^{2}$ Roy. Soc. Phil. Trans., vol. 216, p. $23^{8}$. 